\title{
Fast-food consumption, diet quality and body weight: cross-sectional and prospective associations in a community sample of working adults
}

\author{
Timothy L Barnes ${ }^{1, *}$, Simone A French ${ }^{1}$, Nathan R Mitchell ${ }^{1}$ and Julian Wolfson ${ }^{2}$ \\ 'Division of Epidemiology \& Community Health, School of Public Health, University of Minnesota, Twin Cities, \\ Minneapolis, MN 55454, USA: ${ }^{2}$ Division of Biostatistics, School of Public Health, University of Minnesota, Twin \\ Cities, Minneapolis, MN, USA
}

Submitted 29 April 2014: Final revision received 23 January 2015: Accepted 30 April 2015: First published online 15 June 2015

\begin{abstract}
Objective: To examine the association between fast-food consumption, diet quality and body weight in a community sample of working adults.

Design: Cross-sectional and prospective analysis of anthropometric, survey and dietary data from adults recruited to participate in a worksite nutrition intervention. Participants self-reported frequency of fast-food consumption per week. Nutrient intakes and diet quality, using the Healthy Eating Index-2010 (HEI-2010), were computed from dietary recalls collected at baseline and 6 months.

Setting: Metropolitan medical complex, Minneapolis, MN, USA.

Subjects: Two hundred adults, aged 18-60 years.

Results: Cross-sectionally, fast-food consumption was significantly associated with higher daily total energy intake $(\beta=72.5, P=0.005)$, empty calories $(\beta=0.40$, $P=0.006)$ and BMI $(\beta=0.73, P=0.011)$, and lower HEI-2010 score $(\beta=-1.23$, $P=0 \cdot 012)$, total vegetables $(\beta=-0 \cdot 14, P=0.004)$, whole grains $(\beta=-0 \cdot 39, P=0.005)$, fibre $(\beta=-0.83, P=0.002), \mathrm{Mg}(\beta=-6.99, P=0.019)$ and $\mathrm{K}(\beta=-57.5, P=0.016)$. Over 6 months, change in fast-food consumption was not significantly associated with changes in energy intake or BMI, but was significantly inversely associated with total intake of vegetables $(\beta=-0 \cdot 14, P=0 \cdot 034)$.

Conclusions: Frequency of fast-food consumption was significantly associated with higher energy intake and poorer diet quality cross-sectionally. Six-month change in fast-food intake was small, and not significantly associated with overall diet quality or BMI.
\end{abstract}

Intake of food prepared outside the home has increased over the last few decades ${ }^{(1-3)}$. Thirty-six per cent of US adults consume foods and/or beverages from fast-food sources on any given day ${ }^{(2)}$ and fast food comprises $11.3 \%$ of US adults' total daily energy intake ${ }^{(4)}$. Fast food tends to be energy dense, poor in micronutrients, high in glycaemic load, low in fibre and served in large portions ${ }^{(3,5,6)}$. These factors are consistent with the evidence that fast-food consumption may be a significant contributor to poor diet quality and excess body weight in individuals ${ }^{(3)}$.

Cross-sectional studies show associations between frequency of fast-food consumption, energy intake and body weight ${ }^{(3)}$. For example, Jeffery et al. reported a significant positive relationship $\left(0.30 \mathrm{~kg} / \mathrm{m}^{2}\right.$ higher BMI associated with eating fast food one or more times weekly $v$. no fast-food consumption) ${ }^{(7)}$. However, another study found no statistically significant relationship when assessing fast-food consumption and body weight among metropolitan transit workers ${ }^{(8)}$.

Prospectively, greater weight gain is observed among frequent fast-food consumers compared with less frequent fast-food consumers ${ }^{(9-12)}$. For instance, women in the highest tertile of frequency of fast-food restaurant use at baseline gained $0.72 \mathrm{~kg}$ more than women in the lowest tertile of frequency of fast-food restaurant use during a 3-year period $^{(10)}$. In a 15 -year prospective study, participants with frequent (more than twice weekly) visits to fast-food restaurants at baseline and follow-up gained $4.5 \mathrm{~kg}$ more than those with less than once weekly fast-food restaurant use $\mathrm{u}^{(11)}$. Another study found that increases in fast-food consumption over a 3-year period were significantly associated with change in BMI $\left(0.20 \mathrm{~kg} / \mathrm{m}^{2}\right.$ 
increase in BMI per 1 time/week increase of fast-food consumption frequency) ${ }^{(12)}$.

These existing studies provide initial evidence of significant associations between fast food and BMI. However, additional research is needed, especially as it pertains to diet quality. Every 5 years Dietary Guidelines for Americans (DGA) are issued by the US Department of Agriculture and the US Department of Health and Human Services ${ }^{(13)}$. Accompanying the DGA is a set of key recommendations by the US Department of Agriculture for types and amounts of foods to consume at twelve energy intake levels, with limits on energy from solid fats and added sugars ${ }^{(14)}$. The Healthy Eating Index (HEI) is a measure of diet quality in terms of conformance to the $\mathrm{DGA}^{(14)}$. To the best of our knowledge, only a limited number of studies have examined associations between fastfood consumption and diet quality ${ }^{(15-18)}$. Moreover, previous studies have not included detailed measures of dietary intake or examined changes in dietary intake and BMI with respect to fast-food consumption over time. Thus, research is needed to explore the associations between fast-food consumption and specific dietary quality and nutrient measures and body weight. The examination of dietary quality measures will help identify potential dietary pathways, over and above energy intake, between fast-food consumption and obesity risk.

The purpose of the present study was to examine crosssectional associations between fast-food consumption, diet quality and body weight among a free-living sample of working adults. It was hypothesized that frequent fast-food consumption would be associated with higher energy intake, lower HEI score, lower intakes of fruits, vegetables and whole grains, and higher sugar and fat intakes. Moreover, changes over time in fast-food intake were examined to evaluate whether increases in fast-food intake were prospectively associated with decreases in diet quality or increases in energy intake and body weight.

\section{Methods}

\section{Participants}

The study sample included 200 individuals aged 18-60 years who worked at a large metropolitan medical complex and were recruited to participate in a worksite nutrition intervention $^{(19)}$. The study purpose was to examine the effects of weekday exposure to one of three different lunch calorie portions on energy intake and body weight in a free-living sample of adults over 6 months. Individuals were randomized to one of three exposure conditions: a free box lunch of one of three calorie portions; or to a no-free-lunch control group. Evaluation data were collected at baseline before randomization and at 6 months. The study was conducted from September 2010 through February 2013 and approved by the University of Minnesota Institutional Review Board.

Study eligibility criteria included the following: (i) age 18-60 years; (ii) non-smoker; (iii) fluent in English; (iv) not taking medications that affect appetite or body weight; (v) work at the medical complex full time, including during the lunch hours; (vi) not allergic to the foods in the study lunches; (vii) willing to eat the foods in the study lunches; (viii) not currently on a diet to lose weight; (xi) no history of a diagnosed eating disorder; (x) not moving from the area during the next 6 months; (xi) not currently taking part in another research study; and (xii) not currently pregnant, nursing or pregnant in the last 12 months. Two hundred and thirty-three participants were randomized and completed the intervention study. However, the present analysis included only 200 individuals due to the following reasons: (i) removed pregnant/postpartum women ( $n$ 9) who were inadvertently randomized; (ii) removed participants who received bariatric surgery ( $n$ 2) during the study period; and (iii) removed participants with any missing data related to demographics characteristics ( $n$ 16), fast-food consumption $(n 5)$ and diet measures ( $n$ 11) at baseline or follow-up.

\section{Box lunch study}

The details of the box lunch intervention have been published $^{(19)}$. The intervention consisted of MondayFriday lunch box pick-ups by participants at the worksite for a 6-month period. Staff distributed lunch boxes at a central location from 11.00 to 13.00 hours. Participants were required to pick up their own lunch boxes, but were not further instructed about consumption of the lunch. Participants randomized to the control condition did not receive a box lunch and were instructed to continue their usual lunch patterns.

The energy sizes of the experimental conditions were $400 \mathrm{kcal}(1674 \mathrm{~kJ}), 800 \mathrm{kcal}(3347 \mathrm{~kJ})$ and $1600 \mathrm{kcal}$ $(6694 \mathrm{~kJ})$. The research team collaborated with a grocery/ catering retailer to develop the study menus and prepare the foods. The overall goal was to develop menus with specific energy content and highly similar foods of sizes that accommodated the energy requirements of each experimental condition ${ }^{(19)}$.

\section{Measures}

Measures were collected at baseline and 6 months by trained research staff following a standardized protocol ${ }^{(19)}$. On average, the 6-month follow-up visits were 6.7 months after the initial baseline visit (range: 4.73-7.82 months).

\section{Fast-food consumption}

Fast-food consumption was self-reported using the following question: 'How many times per week (7 days) do you eat something from a carryout, delivery or counterservice only restaurant?' Responses were reported in whole numbers by the participant. This question has been used previously in other research studies ${ }^{(20,21)}$. Because the distribution of fast-food consumption was skewed, the final variable was winsorized at the 95th percentile. 


\section{Diet measurements}

Dietary intake was measured using three telephoneadministered $24 \mathrm{~h}$ dietary recalls collected at baseline and at follow-up (a total of six recalls). Dietary recalls were conducted on non-consecutive days (two weekdays and one weekend day; all three within a time window of $21 \mathrm{~d}$ maximum) over the telephone using the Nutrition Data System for Research (NDSR) software (Nutrition Coordinating Center, University of Minnesota, Minneapolis, MN, USA) ${ }^{(22)}$. Trained and certified staff at the Nutrition Coordinating Center collected the recalls. A food portion estimation booklet similar to the Posner two-dimensional food portion poster ${ }^{(23)}$ was provided to participants in advance of the dietary recall for use in portion size estimation. Food group components and selected nutrient data were extracted from NDSR output to create diet quality and nutrient intake measures.

\section{Healthy Eating Index-2010}

The US Department of Agriculture's Healthy Eating Index2010 (HEI-2010) $^{(14)}$ was used to measure dietary quality based on food and nutrient intakes from the three dietary recalls at baseline and follow-up. The HEI-2010 quantifies diet quality in terms of the 2010 DGA $^{(13,14)}$. The HEI-2010 consists of the sum of twelve components, nine adequacy components and three moderation components, and ranges between 0 and 100. The components and scoring standards of the HEI-2010 are illustrated in Table 1. Components included: (i) total fruit; (ii) whole fruit; (iii) total vegetables; (iv) greens and beans; (v) whole grains; (vi) dairy; (vii) total protein foods; (viii) seafood and plant proteins; (ix) fatty acids; (x) refined grains; (xi) sodium; and (xii) empty calories. Scores for each component group are assigned using a density approach (e.g. per $1000 \mathrm{kcal}$ ( $4184 \mathrm{~kJ}$ ) or as a percentage of energy) based on whether or not a participant meets the recommendations outlined by the 2010 DGA. A score of 0 indicates no intake of foods comprising that component group. If a participant meets the recommendations, then a maximum score is assigned. Partial consumption below the 2010 DGA recommendations is assigned a pro-rated score.

\section{Dietary and nutrient intakes}

In addition to the HEI-2010, total daily energy intake (kcal/d) and daily intake of specific nutrients including total carbohydrates, fibre, $\mathrm{Ca}, \mathrm{Mg}, \mathrm{K}, \mathrm{Na}$, sugar and percentage of energy from cholesterol, fat, saturated fat and protein were examined to complement the diet quality assessment.

\section{Body weight and BMI}

Body weight was measured to the nearest $0 \cdot 1 \mathrm{~kg}$ using a calibrated electronic scale (Befour Inc., Saukville, WI, USA) with participants wearing light clothing and no shoes. Height was measured to the nearest $0 \cdot 1 \mathrm{~cm}$ with a wall-mounted stadiometer. All measures were performed in duplicate. If the two measures differed by $\geq 1 \mathrm{~cm}$ or $\geq 0.5 \mathrm{~kg}$, a third measurement was taken. The mean values of the two measures in closest agreement were used in analyses. Height measurements were converted from centimetres to metres and BMI was calculated as weight/height ${ }^{2}\left(\mathrm{~kg} / \mathrm{m}^{2}\right)$.

\section{Covariates}

Covariates included both self-reported demographic information and objectively measured physical activity data.

Table 1 Healthy Eating Index-2010 (HEl-2010) components and standards for scoring*

\begin{tabular}{|c|c|c|c|}
\hline Component & $\begin{array}{l}\text { Maximum } \\
\text { points }\end{array}$ & Standard for maximum score & Standard for minimum score of 0 \\
\hline \multicolumn{4}{|l|}{ HEl-2010† } \\
\hline \multicolumn{4}{|l|}{ Adequacy } \\
\hline Total fruit $\ddagger$ & 5 & $\geq 0.8$ cup equivalent per 1000 kcall|II & No fruit \\
\hline Whole fruit§ & 5 & $\geq 0.4$ cup equivalent per $1000 \mathrm{kcal}$ & No whole fruit \\
\hline Total vegetables\| & 5 & $\geq 1.1$ cup equivalents per $1000 \mathrm{kcal}$ & No vegetables \\
\hline Greens and beansll & 5 & $\geq 0.2$ cup equivalent per $1000 \mathrm{kcal}$ & No dark green vegetables or beans and peas \\
\hline Whole grains & 10 & $\geq 1.5 \mathrm{oz}$ equivalents per $1000 \mathrm{kcal}$ & No whole grains \\
\hline Dairyף & 10 & $\geq 1.3$ cup equivalents per $1000 \mathrm{kcal}$ & No dairy \\
\hline Total protein foods ${ }^{\star \star}$ & 5 & $\geq 2.5 \mathrm{oz}$ equivalents per $1000 \mathrm{kcal}$ & No protein foods \\
\hline Seafood and plant proteins ${ }^{\star \star}, \dagger \dagger$ & 5 & $\geq 0.8 \mathrm{oz}$ equivalent per $1000 \mathrm{kcal}$ & No seafood or plant proteins \\
\hline Fatty acids $\ddagger \ddagger$ & 10 & $(\mathrm{PUFA}+\mathrm{MUFA}) / \mathrm{SFA}>2.5$ & $(P U F A+M U F A) / S F A \leq 1.2$ \\
\hline \multicolumn{4}{|l|}{ Moderation } \\
\hline Refined grains & 10 & $\leq 1.8$ oz equivalents per $1000 \mathrm{kcal}$ & $\geq 4.3 \mathrm{oz}$ equivalents per $1000 \mathrm{kcal}$ \\
\hline Sodium & 10 & $\leq 1.1 \mathrm{~g}$ per $1000 \mathrm{kcal}$ & $\geq 2.0 \mathrm{~g}$ per $1000 \mathrm{kcal}$ \\
\hline Empty calories§§ & 20 & $\leq 19 \%$ of energy & $\geq 50 \%$ of energy \\
\hline
\end{tabular}

*Table adapted from Guenther et al. ${ }^{(14)}$.

†Intakes between the minimum and maximum standards are scored proportionately.

†lncludes fruit juice.

§lncludes all forms except juice.

IIIncludes any beans and peas (legumes) not counted as total protein foods.

TIncludes all milk products, such as fluid milk, yoghurt and cheese, and fortified soya beverages.

${ }^{\star *}$ Beans and peas are included here (and not with vegetables) when the total protein foods standard is otherwise not met.

††Includes seafood, nuts, seeds, soya products (other than beverages) as well as beans and peas counted as total protein foods.

¥¥Ratio of PUFA and MUFA to SFA.

$\S \S$ Calories from solid fats, alcohol and added sugars; threshold for counting alcohol is $>13 \mathrm{~g} / 1000 \mathrm{kcal}$.

$\|I\| 1000 \mathrm{kcal}=4184 \mathrm{~kJ}$. 
Demographic information included age, sex, race/ethnicity, educational level, household income, job type and marital status. Physical activity was measured objectively using a commercially available ActiGraph ${ }^{\mathrm{TM}}$ GT1M accelerometer (ActiGraph, Pensacola, FL, USA) to determine the daily minutes of moderate-to-vigorous physical activity. Valid wear-time criteria were $4 \mathrm{~d}$ days for a minimum of $9 \mathrm{~h} / \mathrm{d}^{(24)}$.

\section{Statistical analyses}

Longitudinal mixed models were used to examine the cross-sectional and prospective associations between fast-food consumption and all outcomes, i.e. total energy intake, overall diet quality based on the HEI-2010, all other dietary measures and BMI. In these procedures, each dependent outcome measure was modelled as a function of fast-food consumption at baseline and change in fast-food consumption, thus capturing the relationship between fast-food consumption at baseline and the outcome as well as whether a change in fast-food consumption was associated with the outcome prospectively. When modelling baseline values of dependent variables, the change in fast-food consumption at baseline is equal to zero in the modelling procedure. When modelling follow-up values of dependent variables, the change in fast-food consumption at follow-up is the difference between fast-food consumption at follow-up and baseline.

Each model was adjusted for the covariates age, sex, race/ ethnicity, education level, income, job type, martial/partner status and physical activity to control for associations with fast-food consumption, diet quality and BMI. Physical activity was included to account for any possible association with body weight and energy balance. Follow-up time, which represented the exact time in months between baseline and follow-up data collection, was also included in models. Finally, treatment group and energy intake were included in models to account for any effect of the intervention and total daily energy consumed. All analyses were performed using the statistical software package SAS version 9.3.

\section{Results}

On average, participants were 43 years of age at baseline, $66 \%$ were female and the majority were non-Hispanic White (Table 2). Nearly $54 \%$ were college graduates and $78 \%$ earned more than \$US 40000 in annual income. Fifty-nine per cent were married or living with a partner. The mean BMI was $29.9 \mathrm{~kg} / \mathrm{m}^{2}$ at baseline and moderate-to-vigorous physical activity was $28.0 \mathrm{~min} / \mathrm{d}$. The average daily total energy intake at baseline and follow-up was 2026 and $1919 \mathrm{kcal} / \mathrm{d}$ (8475 and $8029 \mathrm{~kJ} / \mathrm{d}$ ), respectively. The mean frequency of fast-food consumption was 1.8 times/week at baseline. The overall mean change in fast-food consumption between baseline and follow-up was very small at -0.10 times/week, reflecting the fact that nearly $46 \%$ of study participants did not change fast-food consumption from baseline to follow-up. However,
$30 \%$ of participants did reduce their fast-food consumption by some amount (mean -1.68 (SD 1.24) times/week).

The unadjusted mean values for dietary measures at baseline and follow-up are shown in Table 3. The mean overall HEI-2010 scores were 58.8 and $60 \cdot 5$, respectively. Only a small number of dietary quality and nutrient intake measures differed significantly from baseline to follow-up. Specifically, there were significantly higher scores at followup compared with baseline for the following HEI-2010 components: total fruit, whole fruit, total vegetables, greens and beans, and percentage of energy from protein. In addition, the score for the HEI-2010 fatty acids component and the intake of total carbohydrates were significantly lower at follow-up compared with baseline.

Table 4 shows the results of the longitudinal mixed models, which separate the cross-sectional effect of fast-food consumption at baseline from the prospective effect of change in fast-food consumption. Significant positive crosssectional associations were observed between baseline fast-food consumption and total energy intake $(\beta=72.5$, $P=0.005)$ and BMI $(\beta=0.73, P=0.011)$. Thus, for every additional episode of fast-food consumption per week, the values for total energy intake and BMI were significantly higher by $72.5 \mathrm{kcal} / \mathrm{d}(303 \mathrm{~kJ} / \mathrm{d})$ and a $0.73 \mathrm{~kg} / \mathrm{m}^{2}$, respectively. Other dietary measures had significantly negative crosssectional associations with fast-food consumption including overall HEI-2010 diet quality $(\beta=-1.23, \quad P=0.012)$, the HEI-2010 components total vegetables $(\beta=-0 \cdot 14, P=0 \cdot 004)$ and whole grains $(\beta=-0.39, P=0.005)$, and the nutrient intakes fibre $(\beta=-0.83, P=0.048), \operatorname{Mg}(\beta=-6.99, P=0.019)$ and $\mathrm{K}(\beta=-57 \cdot 5, P=0 \cdot 016)$. A significant association was also observed between fast-food frequency and the HEI-2010 component empty calories. A decrease in the HEI-2010 component score for empty calories reflects an increase in empty calories per 2010 DGA recommendations. Thus, the direction of the association has been changed in the results to reflect this inverse relationship $(\beta=0 \cdot 40, P=0 \cdot 006)$.

Only one dietary measure, the HEI-2010 component score for total vegetables, had a significant negative prospective relationship with the change in fast-food consumption $(\beta=-0 \cdot 14, P=0.0340)$. Thus, as fast-food consumption increased, the consumption of fruits and vegetables decreased. Lastly, neither overall HEI-2010 diet quality nor BMI over time was significantly associated with change in fast-food consumption.

\section{Discussion}

Fast-food intake has been shown to be associated with BMI and excess weight gain $^{(3)}$. The present results contribute additional details about the potential effects of fast food on dietary quality, with implications for dietary pathways to weight gain or obesity. The study found that cross-sectionally, more frequent fast-food consumption is associated with higher energy intake, intake of fewer fruits 
Table 2 Descriptive characteristics of the study participants: a community sample of working adults ( $n$ 200) aged 18-60 years taking part in worksite nutrition intervention in a large metropolitan medical complex, Minneapolis, MN, USA, September 2010-February 2013

\begin{tabular}{|c|c|c|}
\hline & Baseline & Follow-up \\
\hline \multicolumn{3}{|l|}{ Demographics } \\
\hline \multicolumn{3}{|l|}{ Age (years) } \\
\hline Mean & $43 \cdot 0$ & \\
\hline SD & $11 \cdot 2$ & \\
\hline \multicolumn{3}{|l|}{ Sex $(\%)$} \\
\hline Male & $34 \cdot 0$ & \\
\hline Female & $66 \cdot 0$ & \\
\hline \multicolumn{3}{|l|}{ Race/ethnicity (\%) } \\
\hline Non-Hispanic White & $68 \cdot 0$ & \\
\hline Other & $32 \cdot 0$ & \\
\hline \multicolumn{3}{|l|}{ Education (\%) } \\
\hline High school/GED/vocational & $16 \cdot 0$ & \\
\hline Some college & $30 \cdot 5$ & \\
\hline College graduate and beyond & 53.5 & \\
\hline \multicolumn{3}{|l|}{ Job type (\%) } \\
\hline Admin/executive & 12.5 & \\
\hline Clerical/admin/technical & 37.5 & \\
\hline Patient care & 33.5 & \\
\hline Service/labour & 4.5 & \\
\hline Other & $9 \cdot 0$ & \\
\hline Missing & $3 \cdot 0$ & \\
\hline \multicolumn{3}{|l|}{ Annual income (\%) } \\
\hline$\leq \$$ US 40000 & 22.5 & \\
\hline$>\$$ US 40000 and $\leq \$$ US 80000 & $39 \cdot 0$ & \\
\hline$>\$$ US 80000 & 38.5 & \\
\hline \multicolumn{3}{|l|}{ Married/living with partner (\%) } \\
\hline Yes & $59 \cdot 0$ & \\
\hline No & $41 \cdot 0$ & \\
\hline \multicolumn{3}{|l|}{ BMI } \\
\hline \multicolumn{3}{|l|}{ BMI $\left(\mathrm{kg} / \mathrm{m}^{2}\right)$} \\
\hline Mean & 29.9 & $30 \cdot 1$ \\
\hline SD & $6 \cdot 5$ & $6 \cdot 5$ \\
\hline \multicolumn{3}{|l|}{ Physical activity } \\
\hline \multicolumn{3}{|c|}{ Moderate-to-vigorous physical activity (min/d) } \\
\hline Mean & $28 \cdot 0$ & $28 \cdot 7$ \\
\hline SD & $17 \cdot 0$ & 18.8 \\
\hline \multicolumn{3}{|l|}{ Energy intake } \\
\hline \multicolumn{3}{|l|}{ Total energy intake (kcal/d) } \\
\hline Mean & $2026 \cdot 2$ & 1919.4 \\
\hline SD & 675.9 & 604.5 \\
\hline \multicolumn{3}{|l|}{ Total energy intake $(\mathrm{kJ} / \mathrm{d})$} \\
\hline Mean & 8477 & 8031 \\
\hline SD & 2828 & 2529 \\
\hline \multicolumn{3}{|l|}{ Fast-food consumption } \\
\hline \multicolumn{3}{|c|}{ Frequency of fast-food consumption (per week) } \\
\hline Mean & 1.75 & 1.66 \\
\hline & 1.49 & 1.43 \\
\hline \multicolumn{3}{|c|}{ Change in fast-food consumption from baseline (per week) } \\
\hline Mean & 0 & -0.10 \\
\hline SD & 0 & 1.3 \\
\hline
\end{tabular}

GED, General Educational Development.

and vegetables and whole grains, lower overall HEI-2010 diet quality score, more empty calories and less fibre. In addition, an increase in fast-food consumption over time was associated with a decrease in vegetable intake. However, no associations were found between fast-food consumption and overall diet quality or weight gain prospectively over 6 months.

These results are consistent with those of previous studies that found a positive association between frequency of fastfood intake and total energy intake ${ }^{(10,25,26)}$. The results of the present study further show that higher fast-food consumption is associated with a lower overall HEI-2010 diet quality, lower intake of fruits and vegetables and whole grains, and higher intake of empty calories. To the best of our knowledge, the current study is the first one to examine frequency of fast-food consumption and the HEI-2010 diet quality measure and its components. However, in a report by the US Department of Agriculture using national data, food away from home was associated with higher daily energy intake and lower diet quality using the HEI-2005 ${ }^{(17)}$.

Previous prospective studies examining the association between fast-food consumption and BMI found 
Table 3 Dietary measures of the study participants: a community sample of working adults $(n 200)$ aged $18-60$ years taking part in worksite nutrition intervention in a large metropolitan medical complex, Minneapolis, MN, USA, September 2010-February 2013

\begin{tabular}{|c|c|c|c|c|}
\hline & \multicolumn{2}{|c|}{ Baseline } & \multicolumn{2}{|c|}{ Follow-up } \\
\hline & Mean & SD & Mean & SD \\
\hline \multicolumn{5}{|l|}{ Diet quality based on HEI-2010 } \\
\hline $\begin{array}{l}\text { Overall HEI-2010 score } \\
\text { By HEI-2010 component }\end{array}$ & $58 \cdot 8$ & $12 \cdot 1$ & 60.5 & $11 \cdot 2$ \\
\hline Total fruit ${ }^{*}$ & 2.02 & 1.60 & $2 \cdot 39$ & 1.57 \\
\hline Whole fruit* & 2.32 & 1.92 & 3.12 & 1.83 \\
\hline Total vegetables* & 3.11 & 1.31 & 3.61 & $1 \cdot 18$ \\
\hline Greens and beans* & $2 \cdot 14$ & $2 \cdot 11$ & 2.99 & $2 \cdot 14$ \\
\hline Whole grains & 4.56 & 3.07 & 4.45 & $3 \cdot 26$ \\
\hline Dairy & $6 \cdot 17$ & 2.80 & 6.41 & 2.77 \\
\hline Total protein foods & 4.57 & 0.87 & 4.71 & 0.66 \\
\hline Seafood and plant proteins & 2.68 & 2.07 & 2.42 & 2.02 \\
\hline Fatty acids* & 4.33 & $2 \cdot 83$ & 3.77 & 2.66 \\
\hline Refined grains & 6.55 & 3.12 & 6.23 & 3.07 \\
\hline Sodium & $4 \cdot 14$ & 3.08 & 3.87 & 3.02 \\
\hline Empty calories & $16 \cdot 3$ & 3.6 & $16 \cdot 5$ & $3 \cdot 1$ \\
\hline \multicolumn{5}{|l|}{ Nutrient intakes } \\
\hline$\%$ of energy from cholesterol & $47 \cdot 0$ & 7.5 & $46 \cdot 3$ & 6.9 \\
\hline$\%$ of energy from fat & 33.9 & $6 \cdot 2$ & 33.6 & $6 \cdot 1$ \\
\hline$\%$ of energy from saturated fat & 11.4 & 2.6 & $11 \cdot 8$ & $3 \cdot 0$ \\
\hline$\%$ of energy from protein* & $16 \cdot 6$ & 3.6 & $17 \cdot 9$ & 4.3 \\
\hline Total carbohydrate $(\mathrm{g})^{\star}$ & $242 \cdot 2$ & 87.8 & $227 \cdot 0$ & $79 \cdot 2$ \\
\hline Fibre $(\mathrm{g})$ & $19 \cdot 2$ & 7.9 & $18 \cdot 1$ & $7 \cdot 3$ \\
\hline $\mathrm{Ca}(\mathrm{mg})$ & $940 \cdot 7$ & $402 \cdot 2$ & 945.4 & $422 \cdot 5$ \\
\hline $\mathrm{Mg}(\mathrm{mg})$ & 294.9 & 111.4 & 284.7 & $108 \cdot 1$ \\
\hline $\mathrm{K}(\mathrm{mg})$ & $2599 \cdot 0$ & $917 \cdot 9$ & $2491 \cdot 7$ & 863.4 \\
\hline $\mathrm{Na}(\mathrm{mg})$ & 3328.9 & $1196 \cdot 2$ & $3201 \cdot 7$ & $1055 \cdot 7$ \\
\hline Sugar (g) & $101 \cdot 3$ & 48.9 & 94.3 & 45.5 \\
\hline
\end{tabular}

HEI-2010, Healthy Eating Index-2010.

*Significant difference between baseline and follow-up (ANOVA), $P<0.05$.

significant positive associations between fast-food consumption and increases in body weight ${ }^{(10,11)}$. However, the present study observed no significant prospective relationship between change in fast-food consumption and change in BMI. Possible reasons for this finding could be that the study duration ( 6 months) was too short to observe change in frequency of fast-food consumption. Previous studies examined the association between fast-food consumption and weight change over much longer time periods (e.g. 3 to 15 years) ${ }^{(10-12)}$. However, the study by Duffy et al. also observed a small change $(-0.16$ times/week) in fast-food consumption over a 3year period, despite a much larger sample size ${ }^{(12)}$. In addition, the mostly overweight and obese sample in the present study might have attenuated the ability to observe associations with fast-food intake (at a minimum cross-sectionally). The association between fast-food consumption and excess weight gain may need to be examined in a larger sample with a wider distribution of body weight, perhaps with more variability in fast-food frequency.

The strengths of the present study include the use of standardized dietary measures collected through the Nutrition Coordinating Center (University of Minnesota) and utilization of the HEI-2010 diet quality assessment tool. Body weight measures were conducted in tandem with the diet measures, so the associations between fast-food reports, dietary intake and measured body weight were examined with a more precise approach than in previous studies. In addition, the present study included both cross-sectional and prospective analyses utilizing longitudinal mixed models. This approach allowed for the examination of both the change in fast-food consumption and the cross-sectional effect of fast-food consumption in the same model controlling for all covariates and included a random intercept to account for within-subject dependence.

Limitations include that the data for the present study were collected as part of a nutrition intervention trial the focus of which was not the evaluation of fast-food intake on dietary outcomes. Thus, frequency of fast-food consumption and diet quality were a part of secondary analyses and not the main focus of that trial. Fast-food intake was self-reported using a single question. Although the measure of fast-food frequency has been used in other large-scale population-based prospective cohort studies ${ }^{(11)}$, it provided limited information about fast-food type or other details that might improve precision and interpretability. In addition, the prospective analyses were limited to one follow-up time point at approximately 6 months. This may have been too short a time period to observe any meaningful change in fast-food consumption or weight change. Finally, our study sample may not be generalizable to all populations. The trial was 
Table 4 Cross-sectional and prospective effect of frequency of fast-food consumption on energy intake, dietary measures and BMl among a community sample of working adults $(n 200)$ aged 18-60 years taking part in worksite nutrition intervention in a large metropolitan medical complex, Minneapolis, MN, USA, September 2010-February 2013

\begin{tabular}{|c|c|c|c|c|c|c|}
\hline \multirow[b]{3}{*}{ Outcomes } & \multicolumn{3}{|c|}{ Cross-sectional effect } & \multicolumn{3}{|c|}{ Prospective effect } \\
\hline & \multicolumn{3}{|c|}{$\begin{array}{l}\text { Frequency of fast-food consumption at baseline } \\
\text { (per week) }\end{array}$} & \multicolumn{3}{|c|}{$\begin{array}{c}\text { Change in fast-food consumption from baseline } \\
\text { (per week) }\end{array}$} \\
\hline & $\beta$ & $\mathrm{SE}$ & $P$ value & $\beta$ & $\mathrm{SE}$ & $P$ value \\
\hline \multicolumn{7}{|l|}{ Energy intake* } \\
\hline Total energy intake (kcal/d) & 72.5 & 25.5 & 0.005 & 30.5 & 28.9 & 0.292 \\
\hline \multicolumn{7}{|l|}{ Diet quality based on HEI-2010ł } \\
\hline $\begin{array}{l}\text { Overall HEI-2010 score } \\
\text { By HEI-2010 component }\end{array}$ & $-1 \cdot 23$ & 0.49 & 0.012 & $-0 \cdot 19$ & 0.56 & 0.740 \\
\hline Total fruit & -0.06 & 0.07 & 0.347 & -0.08 & 0.08 & 0.306 \\
\hline Whole fruit & -0.12 & 0.08 & 0.120 & -0.16 & 0.09 & 0.080 \\
\hline Total vegetables & -0.14 & 0.05 & 0.004 & -0.14 & 0.07 & 0.034 \\
\hline Greens and beans & -0.04 & 0.08 & 0.657 & -0.15 & 0.12 & 0.234 \\
\hline Whole grains & -0.39 & 0.14 & 0.005 & 0.05 & $0 \cdot 16$ & 0.736 \\
\hline Dairy & -0.07 & 0.12 & 0.585 & 0.22 & $0 \cdot 15$ & 0.135 \\
\hline Total protein foods & -0.02 & 0.03 & 0.567 & 0.02 & 0.04 & 0.727 \\
\hline Seafood and plant proteins & -0.08 & 0.08 & 0.332 & -0.20 & $0 \cdot 12$ & 0.085 \\
\hline Fatty acids & -0.02 & 0.12 & 0.854 & 0.05 & 0.15 & 0.746 \\
\hline Refined grains & 0.05 & 0.13 & 0.708 & 0.17 & 0.17 & 0.316 \\
\hline Sodium & 0.06 & 0.13 & 0.640 & 0.03 & $0 \cdot 17$ & 0.857 \\
\hline Empty caloriest & 0.40 & 0.14 & 0.006 & -0.03 & $0 \cdot 16$ & 0.867 \\
\hline \multicolumn{7}{|l|}{ Nutrient intakes $\ddagger$} \\
\hline$\%$ of energy from cholesterol & -0.26 & 0.34 & 0.439 & -0.16 & 0.33 & 0.631 \\
\hline$\%$ of energy from fat & 0.39 & 0.27 & 0.150 & -0.14 & 0.32 & 0.674 \\
\hline$\%$ of energy from saturated fat & 0.20 & 0.12 & 0.109 & -0.06 & $0 \cdot 15$ & 0.699 \\
\hline$\%$ of energy from protein & -0.15 & 0.17 & 0.374 & 0.11 & 0.20 & 0.588 \\
\hline Total carbohydrate $(\mathrm{g})$ & -1.75 & $1 \cdot 77$ & 0.324 & -1.42 & 1.73 & 0.411 \\
\hline Fibre $(\mathrm{g})$ & -0.83 & 0.26 & 0.002 & -0.36 & 0.28 & 0.211 \\
\hline $\mathrm{Ca}(\mathrm{mg})$ & -11.7 & $13 \cdot 3$ & 0.380 & $25 \cdot 6$ & $15 \cdot 6$ & 0.104 \\
\hline $\mathrm{Mg}(\mathrm{mg})$ & -6.99 & 2.95 & 0.019 & 0.76 & 3.59 & 0.832 \\
\hline $\mathrm{K}(\mathrm{mg})$ & -57.5 & 23.6 & 0.016 & -7.25 & $27 \cdot 8$ & 0.795 \\
\hline $\mathrm{Na}(\mathrm{mg})$ & -18.9 & 28.2 & 0.505 & $-21 \cdot 8$ & $36 \cdot 8$ & 0.554 \\
\hline Sugar (g) & 0.98 & 1.54 & 0.527 & -0.001 & 1.55 & 1.000 \\
\hline \multicolumn{7}{|l|}{ BMI§ } \\
\hline BMl $\left(\mathrm{kg} / \mathrm{m}^{2}\right)$ & 0.73 & 0.28 & 0.011 & -0.02 & 0.05 & 0.744 \\
\hline
\end{tabular}

HEI-2010, Healthy Eating Index-2010.

Significant associations are shown in bold font.

${ }^{*}$ Adjusted for age, sex, race/ethnicity, education, job type, income, partner, physical activity, BMl, time of follow-up and treatment group.

†Direction of association changed to reflect use of component score in HEl-2010 scoring standards.

$\ddagger$ Adjusted for age, sex, race/ethnicity, education, job type, income, partner, physical activity, BMl, energy intake, time of follow-up and treatment group.

§Adjusted for age, sex, race/ethnicity, education, job type, income, partner, physical activity, energy intake, time of follow-up and treatment group.

conducted in a health-care worksite and the participants were predominantly female, White and educated. However, the recruited sample did include significant proportions of men, non-White racial/ethnic groups and different job types.

The present study provides meaningful detail on dietary quality associated with fast-food consumption. The results are consistent with previous studies and provide additional nuanced findings about diet quality and specific components associated with fast-food intake. Given the association between the frequency of fast-food consumption and diet quality, it is possible that fast-food consumption might displace healthful food choices for adults. Foods available at fast-food restaurants are energy dense, high in fat and low in fruits and vegetables and fibre ${ }^{(27,28)}$. Strategies in public health research to either prevent or reduce the frequency of fast-food consumption are warranted to improve energy balance and diet quality in adults. Efforts have been made to encourage the fast-food industry to improve the nutritional quality of their menu offerings, including limiting the use of oils containing trans-fatty acids and lowering $\mathrm{Na}$ content of food items, and to display energy (calorie) and nutrient information ${ }^{(27)}$. However, despite these recent efforts, limiting fast-food consumption may be the best public health approach to improve diet quality and reduce obesity risk.

\section{Acknowledgements}

Financial support: This research was supported by the National Institutes of Health (NIH), National Institute Diabetes and Digestive and Kidney Diseases (NIDDK) (grant number R01DK081714). The NIH/NIDDK had no role in the design, analysis or writing of this article. Conflict of interest: None. Authorship: S.A.F. conceptualized and designed the intervention study. T.L.B. drafted the manuscript and performed the primary statistical analyses. N.R.M. contributed to the 
development of the study and measurement protocols. J.W. contributed to the statistical analyses. All authors contributed to the writing of the final manuscript. Ethics of buman subject participation: This research was approved by the University of Minnesota Institutional Review Board.

\section{References}

1. Jaworowska A, Blackham T, Davies IG et al. (2013) Nutritional challenges and health implications of takeaway and fast food. Nutr Rev 71, 310-318.

2. Powell LM, Nguyen BT \& Han E (2012) Energy intake from restaurants: demographics and socioeconomics, 2003-2008. Am J Prev Med 43, 498-504.

3. Rosenheck R (2008) Fast food consumption and increased caloric intake: a systematic review of a trajectory towards weight gain and obesity risk. Obes Rev 9, 535-547.

4. Fryar CD \& Ervin RB (2013) Caloric Intake From Fast Food Among Adults: United States, 2007-2010. NCHS Data Brief no. 114. Hyattsville, MD: National Center for Health Statistics.

5. Lachat C, Nago E, Verstraeten R et al. (2012) Eating out of home and its association with dietary intake: a systematic review of the evidence. Obes Rev 13, 329-346.

6. Rydell SA, Harnack LJ, Oakes JM et al. (2008) Why eat at fast-food restaurants: reported reasons among frequent consumers. J Am Diet Assoc 108, 2066-2070.

7. Jeffery RW, Baxter J, McGuire M et al. (2006) Are fast food restaurants an environmental risk factor for obesity? Int $J$ Behav Nutr Phys Act 3, 2.

8. French SA, Harnack LJ, Toomey TL et al. (2007) Association between body weight, physical activity and food choices among metropolitan transit workers. Int J Behav Nutr Phys Act 4, 52.

9. Jeffery RW \& French SA (1998) Epidemic obesity in the United States: are fast foods and television viewing contributing? Am J Public Health 88, 277-280.

10. French SA, Harnack L \& Jeffery RW (2000) Fast food restaurant use among women in the Pound of Prevention study: dietary, behavioral and demographic correlates. Int J Obes Relat Metab Disord 24, 1353-1359.

11. Pereira MA, Kartashov AI, Ebbeling CB et al. (2005) Fast-food habits, weight gain, and insulin resistance (the CARDIA study): 15-year prospective analysis. Lancet $\mathbf{3 6 5}$, 36-42.

12. Duffey KJ, Gordon-Larsen P, Jacobs DR Jr et al. (2007) Differential associations of fast food and restaurant food consumption with 3-y change in body mass index: the Coronary Artery Risk Development in Young Adults Study. Am J Clin Nutr 85, 201-208.

13. US Department of Agriculture \& US Department of Health and Human Services (2010) Dietary Guidelines for Americans, 2010, 7th ed. Washington, DC: US Government Printing Office.
14. Guenther PM, Casavale KO, Reedy J et al. (2013) Update of the Healthy Eating Index: HEI-2010. J Acad Nutr Diet 113, 569-580

15. Schroder H, Fito M \& Covas MI (2007) Association of fast food consumption with energy intake, diet quality, body mass index and the risk of obesity in a representative Mediterranean population. Br J Nutr 98, 1274-1280.

16. Moore LV, Diez Roux AV, Nettleton JA et al. (2009) Fast-food consumption, diet quality, and neighborhood exposure to fast food: the multi-ethnic study of atherosclerosis. Am J Epidemiol 170, 29-36.

17. Todd JE, Mancino L \& Lin B-H (2010) The Impact of Food Away From Home on Adult Diet Quality. Economic Research Report no. ERR-90. Washington, DC: US Department of Agriculture, Economic Research Service.

18. Wilcox S, Sharpe PA, Turner-McGrievy G et al. (2013) Frequency of consumption at fast-food restaurants is associated with dietary intake in overweight and obese women recruited from financially disadvantaged neighborhoods. Nutr Res 33, 636-646.

19. French SA, Mitchell NR, Wolfson J et al. (2014) Portion size effects on weight gain in a free living setting. Obesity (Silver Spring) 22, 1400-1405.

20. French SA, Harnack LJ, Hannan PJ et al. (2010) Worksite environment intervention to prevent obesity among metropolitan transit workers. Prev Med 50, 180-185.

21. French SA, Gerlach AF, Mitchell NR et al. (2011) Household obesity prevention: Take Action - a group-randomized trial. Obesity (Silver Spring) 19, 2082-2088.

22. Nutrition Coordinating Center, University of Minnesota (2014) Nutrition Data System for Research. http://www.ncc. umn.edu/products/ndsr.html (accessed August 2014).

23. Posner B, Smigelski C, Duggal A et al. (1992) Validation of two-dimensional models for estimation on portion size in nutrition research. J Am Diet Assoc 92, 738-741.

24. Colley R, Connor GS \& Tremblay MS (2010) Quality control and data reduction procedures for accelerometryderived measures of physical activity. Health Rep 21, 63-69.

25. French SA, Story M, Neumark-Sztainer D et al. (2001) Fast food restaurant use among adolescents: associations with nutrient intake, food choices and behavioral and psychosocial variables. Int J Obes Relat Metab Disord 25, $1823-1833$.

26. Guthrie JF, Lin BH \& Frazao E (2002) Role of food prepared away from home in the American diet, 1977-78 versus 1994-96: changes and consequences. J Nutr Educ Behav 34, 140-150.

27. Hearst MO, Harnack LJ, Bauer KW et al. (2013) Nutritional quality at eight US fast-food chains: 14-year trends. $\mathrm{Am} \mathrm{J}$ Prev Med 44, 589-594.

28. Bauer KW, Hearst MO, Earnest AA et al. (2012) Energy content of US fast-food restaurant offerings: 14-year trends. Am J Prev Med 2012 43, 490-497. 